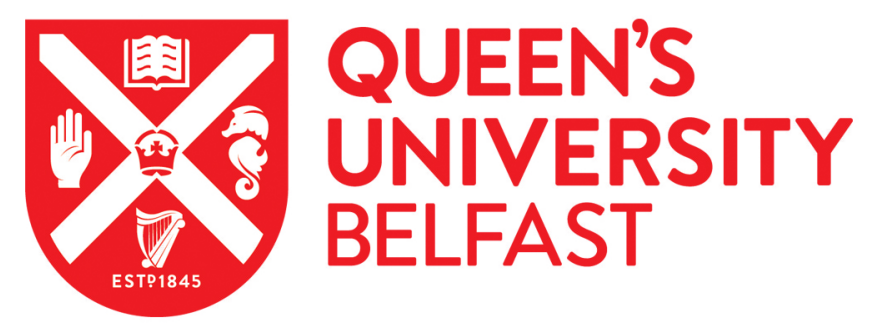

\title{
Why did fewer people change address in England and Wales in the 2000 s than in the 1970s? Evidence from an analysis of the ONS Longitudinal Study
}

Shuttleworth, I., Cooke, T., \& Champion, T. (2018). Why did fewer people change address in England and Wales in the 2000s than in the 1970s? Evidence from an analysis of the ONS Longitudinal Study. Population, Space and Place. https://doi.org/10.1002/psp.2167

Published in:

Population, Space and Place

Document Version:

Peer reviewed version

Queen's University Belfast - Research Portal:

Link to publication record in Queen's University Belfast Research Portal

Publisher rights

(c) 2018 John Wiley \& Sons Ltd.

This work is made available online in accordance with the publisher's policies. Please refer to any applicable terms of use of the publisher.

\section{General rights}

Copyright for the publications made accessible via the Queen's University Belfast Research Portal is retained by the author(s) and / or other copyright owners and it is a condition of accessing these publications that users recognise and abide by the legal requirements associated with these rights.

Take down policy

The Research Portal is Queen's institutional repository that provides access to Queen's research output. Every effort has been made to ensure that content in the Research Portal does not infringe any person's rights, or applicable UK laws. If you discover content in the Research Portal that you believe breaches copyright or violates any law, please contact openaccess@qub.ac.uk. 


\title{
Why did fewer people change address in England and Wales in the 2000s than in the 1970s? Evidence from an analysis of the ONS Longitudinal Study
}

\begin{abstract}
The paper explores why internal migration rates fell in England and Wales between 1971-81 and 200111. It considers all-address changing rates, short-distance migration (address changes involving moves of $10 \mathrm{~km}$ or less) and long-distance migration (moves of $50 \mathrm{~km}$ or more). It does so by using the BlinderOaxaca method to decompose the differences between the two time periods into a compositional component (changes in the aggregate migration rate attributable to increases or decreases in more or less migratory groups of the population) and a rate component - the extent to which these population groups behave differently in the two time periods. The analysis finds that changing population structure since the 1970s does not fully account for the observed decreases. Instead, it seems that changed migratory behaviour and in particular a large general downward effect that cuts across all population groups is the most important component. The greater decrease in address changing observed for all moves and those of less than $10 \mathrm{~km}$ (compared with longer-distance moves) points the search for further explanations in the direction of factors known to be associated with short-distance moves such as the housing market and this is identified as an avenue for more research.
\end{abstract}

\section{Introduction}

The existence of a long-term decline in internal migration rates in the USA across all spatial scales has become well established in the literature (Cooke, 2011, 2013; Kaplan \& Schulhofer-Wohl, 2012; Wolf \& Longino, 2005). Less well known, but starting to draw attention, is a fall in migration rates as measured by address changes in England and Wales since the 1970s. This mirrors the US experience in certain respects in that it is long term and durable beyond the vagaries of economic cycles, but also in that it is seen mainly over shorter distances of less than $10 \mathrm{~km}$ in the UK (Champion \& Shuttleworth, 2016a, 2016b) and for within-county moves in the USA, but it differs in that no sustained decline in long-distance moves has been observed in the UK case. Such migratory falls, wherever they occur, are unexpected. After all, we are said to be living in an 'age of migration', a world that is 'on the move', and in societies that are becoming more spatially mobile with greater fluidity and transience. These assumptions are deeply embedded in migration and social theory where increasing income, social development, and progress away from sedentary pre-industrial societies to industrial, modern, and indeed post-modern societies are commonly seen as eroding ties to community and place and leading to greater population mobility (Ravenstein, 1885; Zelinsky, 1971; Fischer, 2002; Sheller \& Urry, 2006). The evidence that internal migration is decreasing in at least some countries does not disprove these theories. However, it does raise interesting questions since address changes - internal migration - are an important element in the spatial and social mobility of populations regardless of other mobilities on other temporal and spatial scales (see Champion, Cooke \& Shuttleworth, 2018, especially chapter 1). 
The growing evidence that some national populations are becoming less rather than more mobile therefore raises some interesting theoretical questions. The factors that underlie decreasing rates of address change are so far not well understood although there are many hypotheses. These range from structural changes in population composition in terms of age, housing tenure, and educational attainment through the restructuring of labour markets (for example, the rise of two-earner households and the decline of functional Fordist industrial regions), to changed migration behaviour arising from better transportation and ICT (for example, the substitution of address changes by longerdistance commuting, and the use of ICTs (Cooke \& Shuttleworth, 2017)). This is by no means an exhaustive list, and there is scope for further research to better understand why and how people are changing address less frequently.

The implications of decreasing address change rates are, if anything, less well understood than the causes of these declines but nevertheless it is possible to discern some of their impacts. In the economic sphere, the UK Government in 2015 , for instance, attributed some of the slow growth in labour productivity, relative to international competitors, to the relative spatial immobility of the population and to housing shortages (HM Treasury, 2015). For social policy, the increasing residential immobility of the population might have complex and contradictory effects. On the one hand, it may strengthen local communities as stable populations are more likely to promote bonding social capital. Furthermore, individuals who remain where they are, if not 'frustrated leavers', may well be happier than people who move on multiple occasions. However, the reverse of increasing community strength and ties is that geographical and social silos are maintained and even increased as people live with others with the same characteristics and are less likely to mix residentially.

The paper sets its main task as probing further the main dimensions of the decline in address changes in England and Wales since the 1970s. In particular, following Cooke (2011), it seeks to assess the relative importance of changes in the composition of the population (in other words shifts between the more and the less migratory groups in the population) versus observed differences in migration behaviour (in other words the changing address-changing rates of different demographic groups) as drivers of the decrease in short-distance migration.

\section{Literature review}

Differences in levels of migration, measured in aggregate between populations, are a consequence of the demographic structure of these populations and the sum of individual migration propensities, in other words population composition and rate effects. The latter are the result of individual migration decisions, some of which are realised and some frustrated, and yet others which were not desired but 
were perhaps enforced by circumstance. The former are changes in population structure that influence overall migration levels - for example, an increase in the proportion of young people should lead to a higher migration rate since these age groups are on average more migratory than older people. The paper does not deal with how the psychology of migration decisions has changed through time and whether the migration declines in the UK and the USA have been caused, for instance, by an increase in the proportion of frustrated non-movers. It cannot deal with causality in this sense. It concentrates instead on changing population structures, and on changes in migration behaviour as measured by actual moves, weighing their relative importance in altering rates of address change in England and Wales since the 1970s, dealing thereby with causality in a more aggregate way. Fortunately, there is a wide literature on the demographic correlates of migration, and it is this which is most relevant to the concerns of this analysis since it outlines those population groups which are more or less migratory and whose changing relative compositional shares will impact on changing migration levels.

Champion (2005) summarises some of these patterns. A good starting point is the clear differences in migration behaviour by age with younger people being more migratory than older people since they are more likely to change address as they make employment- and education-related transitions and also leave the parental home, something also noted by Thomas, Stillwell and Gould (2015). There are also differentials by housing tenure with people in private-rented accommodation being more spatially mobile than those in social- rented or owner-occupied housing (Coulter, van Ham \& Findlay, 2015). Economic activity is also a classic factor associated with migration. Champion (2005) observes that people who are unemployed are more likely to change address than others. However, others have suggested that unemployed people probably lack economic resources to enable moves and are hence more likely to remain in place to take advantage of local community support (Kitching, 1990; Green, 2018). The ground is firmer when education is considered since there is a strong consensus that having any qualifications increases the propensity to change address over someone with no qualifications and that this propensity increases as educational attainment increases (Champion, 2005). Similarly, social class and occupation appear to influence propensities to change address with those in higher-status occupations and those in higher social classes being more likely to move than those, for example, in manual or elementary occupations. Finally, marital status is also important. Single people, whether previously married or not, tend to change address more often than married people. Shifts in partnership formation/dissolution are therefore likely to influence the overall rate of address changing in a population.

This body of literature also indicates how the correlates of, and reasons for, changing address vary by distance, something which is of key importance given the difference between the USA and England 
and Wales in their migration declines. Coulter and Scott (2015) present a good starting point in their discussion of how the motivations for changing address vary by distance. Typically, longer-distance moves are associated with younger people and employment- and education-related reasons whereas shorter-distance address changes are more common amongst the middle-aged and older parts of the population and are often prompted by factors associated with housing, neighbourhood and environment. Shorter-distance moves are also associated with less advantaged people such as those who are unemployed or in social-rented accommodation. These observations are corroborated when the correlates of longer- versus shorter-distance moves are considered. Here, the more skilled and educated are more likely to move over longer distances as also are military personnel (Gordon, 1982; Niedomysl, 2011). Private renters are mobile over all spatial scales and are more likely in particular to migrate longer distances than social renters.

These relationships are observed empirically when the rates of (a) changing address and (b) moving over distances of 50km or more in England and Wales 1971-81 and 2001-11 (based on characteristics at the start of each decade) were compared and contrasted by Champion and Shuttleworth (2015). The expected differentials by demographic sub-group for each time period were observed; younger people were more mobile than older, private renters were more migratory than other tenure categories, as were those with degrees compared with those who were not. Furthermore, some groups such as those with degrees were more mobile over ranges of $50 \mathrm{~km}$ than more. However, looking at the pattern of change through time, nearly all population groups had lower migration rates in 2001-11 than in 1971-81.

This discussion leads to some expectations to inform the analysis of the compositional factors that are associated with the decrease in the rate of address changing since 1971. There are two separate but closely-related issues, the decrease in all address changes, and the fall in moves of $10 \mathrm{~km}$ or less which accounts for most of this decline (Champion \& Shuttleworth, 2016b) - in contrast to the position in the USA where moves have declined at all spatial scales. In dealing with these issues, the central concern is whether the changes in the relative size of population groups (for example, the declining proportions of younger people and private renters) have outweighed increases in the size of more mobile sections of the population (for example, those with degrees).

Besides these compositional considerations are questions about the extent to which changes in observed migration behaviour (for example, the changing migratory rates of different population subgroups) act to counteract or reinforce the effects of changes in population composition. There is an extensive literature that seeks to explain the long-term migration decline in the USA in terms of 
changing migration behaviour. This points, amongst other factors, to the rise of 'secular rootedness' (a growing attachment to place, (Cooke, 2011)), the growth of ICTs (Cooke, 2013; Cooke \& Shuttleworth 2017), convergence of regional housing and labour markets (Partridge, Rickman, Olvert \& Ali, 2012), the rise of dual-earner households, and the substitution of housing moves by longerdistance commuting (Champion et al., 2018). These factors might all make people 'stay put' as migration rates fall and behaviour changes through time.

Differences in migration rates between two time periods can therefore be conceptualised as two components, namely shifts in population composition and migration rates. The central aim of this paper is to identify how far the decline in overall migration rates in England and Wales between 197181 and 2001-11 can be explained by changed population composition or by changed behaviour. We tackle this task by applying the Oaxaca-Blinder decomposition method - see later Equations 1 to 9 (Jann 2008) - to data derived from the Office for National Statistics Longitudinal Study (ONS LS).

\section{Data and methods}

Data

As noted by Champion and Shuttleworth (2016b), the ONS LS is particularly suited for answering the questions posed in this paper because it covers a long time period (1971-2011) and it has individuallevel data that can be flexibly analysed to pursue the analysis of differences by place and sociodemographic group and which is required by the Oaxaca-Blinder method. Admittedly, there are some shortcomings with the dataset. It does not, for example, cover the whole UK but only England and Wales and it does not contain information on every address change but only on the transitions between address as recorded at one census and address at the following census. Migration is therefore measured as a single transition over a decade and not as a series of events. The data must also be used with care for analyses through time because of changes between censuses in the structure, coverage, and nature of questions. Some variables, such as age, are unchanging between censuses and are thus easy to use for through-time analyses. Others, such as educational qualifications, change as rapidly as the ever-changing educational system and qualifications framework of England and Wales, and care therefore has to be taken to code them on to a lowest common denominator' to permit comparisons through time. Yet other variables, such as ethnicity and limiting long-term illness, only make their first appearance in 1991 and thus cannot be included in a consistent suite of analytical variables from 1971 onwards. There might also be subtle changes in the social meaning of some variables through time such as those concerning economic activity and the way that people self-report their status. Another issue is that the independent variables used later in the analysis refer to initial conditions at the start of the decade as captured in the census and people may 
change status over the full ten years. Finally, there are problems with the changing enumeration base of the census. Prime amongst these is that students have been enumerated at their term-time address from 2001 onwards rather than their parental home as previously.

However, while these issues mean that considerable care has to be taken in designing an analysis using the ONS LS, they should not obscure and override the considerable strengths of the data. These include the large sample size - $1 \%$ of the population of England and Wales based on four birth dates of 500,000 or more individuals, the high rate of matching (exceeding $95 \%$ ) of eligible persons between censuses (e.g. excluding those who died, were born, and left or entered England and Wales between two census dates), and the relatively long duration (from 1971) covered by the data. Furthermore, one of the weaknesses of the data noted above - information only available on address at the start and the end of the decade - is in some ways a strength since cyclical effects of economic boom and bust tend to average out over a ten-year period in a way they cannot if there is address information only in the year before the census. The 1970s, for instance started with an economic boom in 1972/73 followed by the recessions of $1974 / 75$ and $1979 / 80$ prompted by oil shocks to the UK economy whereas the 2000s saw early economic growth followed by the financial crash of 2007/08 and then by recession. These short-term period effects tend to be averaged out over a ten-year period. Additionally, there is high-quality information on peoples' usual addresses thereby allowing a very good picture of all address changes and flexibility to consider particular distances of address changes.

There were a number of considerations in designing the analytical database. Firstly, the analysis compares and contrasts the address change rates of two groups of sample members, one being ONS LS members who were present in both the 1971 and 1981 Censuses, and the other those who were present in 2001 and 2011. The logic of this is that address changes can only be measured for those for whom we can examine changes between censuses and therefore there must be a start and end point to measure the transition. Secondly, only those aged 16-74 (at the start of each decade) are selected for the analysis. This permits socio-economic variables and educational qualifications - only collected for this age group - to be included in the analysis. It also concentrates on those individuals who are likely to move independently as prime age adults rather than as dependent movers, such as children, who normally will follow their parents. Thirdly, the analysis excludes students from both groups to avoid the problem associated with the 2001 change in the way that students' usual addresses were defined. This affords some degree of consistency but there is no entirely satisfactory answer to this problem since young people, and flows to and from higher education, are an important part of the internal migration scene within the UK and the proportion of students increased through time. Some exploration of the impacts of excluding students was made and it was observed that the overall 
address changing rate fell from $55 \%$ in $1971-81$ to $45 \%$ in $2001-11$ (with students in the sample) to $51.8 \%$ to $41.0 \%$ (without students). The consistent ten percentage point fall encouraged confidence in the robustness of the analytical dataset.

The focus of the paper is on three types of migration as outcome variables; (a) all address changing, (b) moves of $10 \mathrm{~km}$ or less, and (c) moves of $50 \mathrm{~km}$ or more. The rationale for this three-fold choice was that the fall in all-address changing rates appeared to be particularly large, most of the decline was for moves of less than $10 \mathrm{~km}$, and there was an interest in exploring whether short-distance moves contrasted with those over long distance, here defined as $50 \mathrm{~km}$ or more. The all-address change rate in the analytical database fell from $51.8 \%$ to $41.0 \%$ between $1971-81$ and $2001-11$; the respective figures for moves of $50 \mathrm{~km}$ or more and moves of less than $10 \mathrm{~km}$ were from $8.5 \%$ to $7.2 \%$ and $35.1 \%$ to $27.5 \%$.

The independent variables for the analysis are listed in Table 1 which gives definitions and the numbers for each category. They describe individuals at the start of each decade as noted above. Looking first at the set of explanatory variables, age was relatively straightforward and was coded categorically in ten-year age groups. Gender was also easy to define for the analysis. Educational qualifications, reflecting the changing nature of the question between censuses, were more complex and, in the end, a pragmatic choice had to be made to code this variable simply as those who had at least a first degree versus those who did not. Region was defined on a consistent geographical basis of five regions and housing tenure was grouped into four categories of owner occupation (whether owned or buying with a mortgage), private renting, social renting and communal establishments (defined as multi-person households such as care homes, hospitals, or prisons). Marital status was coded to a consistent set of four categories, namely single, married, widowed and divorced. Whether someone was UK-born or not was used as a consistent variable through time. Finally, economic activity and socio-economic group (SEG) were also included and coded to a consistent set of categories. The selection of this set of variables was to some extent pragmatic and driven by what information could be consistently collected from the census in various years but it also was a result of knowledge of the characteristics that are known from the literature to be associated with internal migration and address changing.

$<$ Table 1 about here>

\section{Method}

As outlined in the literature review there are two main direct explanations for the reduction in addresschanging frequencies, whether long-distance or local moving. These are (a) changes in the composition 
of the population and (b) changes in the rate of migration among population subgroups. The analysis therefore aims to estimate the relative contribution of these two components to the changes in aggregate migration rates observed in England and Wales between 1971 and 2011. Specifically, the analysis focuses on how address changes from 1971 to 1981 and from 2001 to 2011 change as a function of rate- and composition-effects as estimated using the Oaxaca-Blinder regression decomposition technique (Blinder, 1973; Oaxaca, 1973). We start by reviewing the conceptual model outlined by Jann (2008) before specifying the actual variables used in this analysis. Consider regression models of the individual probability of changing address $(\mathrm{Y})$ as a function of a vector of individual characteristics $(X)$ in 1971 and 2001:

$$
Y_{i, 1971 \mapsto 1981}=X_{i, 1971} \beta_{1971}+\varepsilon_{i, 1971}
$$

and

$$
Y_{i, 2001 \mapsto 2011}=X_{i, 2001} \beta_{2001}+\varepsilon_{i, 2001}
$$

Then the difference in the aggregate migration rate between 1971-81 and 2001-11 can be written as:

$$
\bar{Y}_{2001 \mapsto 2011}-\bar{Y}_{1971 \mapsto 1981}=\bar{X}_{2001} \beta_{2001}-\bar{X}_{1971} \beta_{1971}
$$

The decomposition is constructed by adding and subtracting each of the following terms:

$$
\begin{aligned}
& \bar{X}_{2001} \beta_{1971} \\
& \bar{X}_{1971} \beta_{1971} \\
& \bar{X}_{1971} \beta_{2001}
\end{aligned}
$$

Consequently,

$$
\begin{aligned}
& \bar{Y}_{2001 \mapsto 2011}-\bar{Y}_{1971 \mapsto 1981}=\bar{X}_{2001} \beta_{2001}-\bar{X}_{1971} \beta_{1971}+\bar{X}_{2001} \beta_{1971}-\bar{X}_{2001} \beta_{1971}+ \\
& \bar{X}_{1971} \beta_{1971}-\bar{X}_{1971} \beta_{1971}+\bar{X}_{1971} \beta_{2001}-\bar{X}_{1971} \beta_{2001}
\end{aligned}
$$

and then rearrange,

$$
\begin{aligned}
& \bar{Y}_{2001 \mapsto 2011}-\bar{Y}_{1971 \mapsto 1981}=\bar{X}_{2001} \beta_{1971}-\bar{X}_{1971} \beta_{1971}+\bar{X}_{1971} \beta_{2001}-\bar{X}_{1971} \beta_{1971}+ \\
& \bar{X}_{2001} \beta_{2001}-\bar{X}_{2001} \beta_{1971}-\bar{X}_{1971} \beta_{2001}+\bar{X}_{1971} \beta_{1971}
\end{aligned}
$$

which finally yields,

$$
\begin{aligned}
& \bar{Y}_{2001 \mapsto 2011}-\bar{Y}_{1971 \mapsto 1981}=\beta_{1971}\left(\bar{X}_{2001}-\bar{X}_{1971}\right)+\left(\beta_{2001}-\beta_{1971}\right) \bar{X}_{1971}+\left(\beta_{2001}-\right. \\
& \left.\beta_{1971}\right)\left(\bar{X}_{2001}-\bar{X}_{1971}\right)
\end{aligned}
$$

Closely following Cooke (2011), the first term on the right hand side (RHS) is an estimate of the effect of changing population composition on the overall change in residential mobility based upon year 1971 parameter estimates (i.e., composition effects). The second term on the RHS is an estimate of the effect of changing parameter estimates on the overall change in residential mobility based upon year 1971 population characteristics (i.e., rate effects). The third term is a residual effect. These values are then reported as percentages by dividing all terms by the overall change in residential mobility rates. 
The estimates for the Oaxaca-Blinder decomposition are implemented using the Oaxaca module (Jann, 2008) for Stata (Statacorp, 2015).

Intuitively, composition effects - the first term on the RHS - relate how changes in the composition of the population affect address changes between 1971 and 2011. For example, it is expected that the composition effect associated with older age categories will be negative; as the share of the population in older age categories increases the overall rate of address changes will decrease since older populations move less often than younger populations. Similarly, rate effects - the second term on the RHS - relate how changes in behaviour among a specific subgroup affect overall differences in address changes between 1971 and 2011. For example, the increased proportion of graduates in 2001, drawn from a wider social background than in 1971, and not as scarce in the 2000s than in the 1970s, may mean that there are different returns to education in the two decades and thus different migration responses; graduates in the 2000s may be more similar to the rest of the population than in the 1970s and their migration rates (and also their relative propensity to move compared to nongraduates) might have fallen.

The explanatory variables are categorical and are thus compared against a base category. This means that the coefficients would vary if set against another base. The findings should therefore not be regarded with spurious precision but as diagnostic and which can be interpreted with reference to the descriptive compositional and rate statistics presented in Table 2 . The models also consider just how starting conditions at the beginning of the decade were related to migration outcomes over the decade. This makes sense in terms of cause and later outcome. However, they do not assess how individuals shift with regard to the explanatory variables through the decade. This also means that sensitivity is needed in interpreting the results. One example is the pattern of change in the composition of the England and Wales housing market where private renting reached a trough in 2001 but increased by the time of the 2011 Census. Some sample members in other housing tenures in 2001 may have drifted into this traditionally more-mobile sector by 2011 , and thus the composition of the population might have shifted in favour of greater migration by the end of the decade; the observed address changes 2001-11 might therefore overestimate the compositional effect of the decline of private renting but correspondingly underestimate the impact of declining migration rate or behavioural effects.

Full model results are presented in an appendix because they are unwieldy, but in Table 3 summary results are presented for all address changes (relative to non-movers), address changes over $50 \mathrm{~km}$ or more (relative to movers of less than $50 \mathrm{~km}$ and non-movers), and address changes of less than $10 \mathrm{~km}$ 
(relative to non-movers and movers of $10 \mathrm{~km}$ or more) with reference where needed to the Appendix tables and Table 2. With over 250,000 members of the sample in each decade virtually all coefficients are statistically significant. We therefore do not discuss statistical significance in detail but rather concentrate on which effects are the largest and thus appear as the most important drivers of changing migration levels.

\section{Results}

Since one of the major themes of the paper is how far changing social and demographic profiles alter migration levels, Table 2 summarises the composition of the England and Wales population in 1971 and 2001 at the start of each decade. The figures in Columns 2 and 3 add to $100 \%$ vertically for each variable. In Columns 5 and 6 they are read horizontally - for example, 53.2\% of males moved in 197181. The changes presented in the table reassuringly present no major surprises although there are some interesting points to note. We see increases in the shares of those who are non-UK born, with degrees, single or divorced, and professional or intermediate, and decreasing proportions of those who are married, private or social renters, or economically inactive, and also age shifts. These are what might be expected given the literature on labour market, social and demographic change. Some initial thoughts on the impact of changing population balances on overall migration rates are possible. Column 5 of this table highlights those sub-groups which had higher rates of address changing than the average in 1971-81. Some of these groups such as those with degrees, who were skilled nonmanual, intermediate, professional, divorced or single grew proportionately over the thirty years from 1971 whereas others whereas others such as private renters and those aged 16-24 decreased. Clearly, there are structural social changes over the medium to long term that are working to push addresschanging rates upwards and others that are acting to push them downwards - the main question is which will win out and what the net effect will then be.

$<$ Table 2 about here>

Of course, changes in total migration rates across a population between two time periods are not just a consequence of changes in the proportions of mobile or immobile groups; they also result from changes in migration rates, in other words alterations in migration behaviour through time. Table 2 provides some insights into these changes. The vast majority of groups register decreases, the only exceptions being private renters and communal dwellers who were more spatially mobile in 2001-11 than in 1971-81 but whose share of the population was lower in 2001 than in 1971. Mention might also be made of those aged 25-34; this group's address-changing rate was only marginally lower than 
in 1971-81 although there are big decreases for older age groups. The picture, however, is one of general decline - address-changing rates have fallen for the vast majority of demographic groups.

Table 3 provides aggregated statistics - once again, full details of the raw output are tabulated in the Appendix. In Table 3, these coefficients are multiplied by 100 to transform them back into terms of the original migration rates per 100 people. Columns 2, 4, and 6 (headed coefficients) show the contribution of each variable to the raw percentage point differentials in migration rates in 1971-81 and 2001-11 and the other columns headed '\%' present this as a percentage contribution. Looking first at all address changes and what can be attributed to population composition it is seen that in total this contributes 3.92 percentage points to the 10.8 percentage point differential. This is just over a third of the differential, the remainder being unexplained by population composition changes but instead by decreases in migration behaviour, including the constant intercept term (at just over $70 \%$ $-7.90 \mathrm{pp}$ of the $10.79 \mathrm{pp}$ decrease), but a roughly $10 \%$ increase from the residual. The main compositional factors that are driving the all-address changing rate down are population ageing (especially those aged 35-44 and those over 65) and the shift to owner occupation from other tenures, particularly private renting. Evidence in support of these more detailed comments can be found in Table A2 of the appendix. These downward compositional pushes outweigh those countervailing compositional changes from increases in the share of the population with degrees, changes in marital status with more single and divorced people (both mobile groups), and SEG with a growth in higherlevel more mobile groups.

$<$ Table 3 about here $>$

However, it cannot be emphasised enough that the majority of the decline in all-address changing rates is attributable to the changed migration behaviour of population sub-groups and the downward pressure of the constant term. The coefficients in Table 3 will vary according to the base categories selected so care is needed in interpreting these results. However, after the Oaxaca-Blinder procedure standardisation it is found that there are falls associated with age and marital status but rate increases for other groups. However, there is a major downward effect associated with the constant term. This can be viewed as a general rate effect that cuts across groups forcing all rates downwards, which is similar to that observed by Cooke (2011) and which he attributes to secular rootedness. The constant does a substantial amount of work in explaining the overall all address-changing decrease so some thoughts about this will be advanced later in the discussion. 
The situation for moves of less than $10 \mathrm{~km}$ is similar to that for all address changing, and moves of 50 or more kilometres in some regards, but differs in other important respects. Address changes in this distance band are compared against people who do not change address or those who move $10 \mathrm{~km}$ or more. The results are similar in that that the majority of the 9.38 percentage point differential between 1971-81 and 2001-11 is accounted for by rate changes rather than changes in population composition. It is also similar in that the ageing of the population is the most important compositional driver of the rate fall and that changing housing tenure also has a major role. The ageing of the population and the shift away from private and social renting to owner occupation seem to have contributed to a fall in address changes in this distance band. Education, however, has an opposite effect to the other two models but this is not unexpected since increasing proportions of graduates will, everything else being equal, increase the proportion of longer-distance movers at the expense of short-distance movers. The coefficient section of the model differs in that mostly it contributes to the migration decrease and the constant has a positive rather than a negative effect. This latter observation suggests that a universal effect is pushing up the share of moves of $10 \mathrm{~km}$ or less relative to the reference categories. Interesting are the strong negative effects of age and region - and inspection of the detailed tables in the appendix suggests that these observations can be explained by rate decreases in the North relative to the South East and the declining migration rates of older groups of the population relative to the reference category of those aged 16 to 24 . The net effect of the residual term is very small.

The interpretation of the model for moves of $50 \mathrm{~km}$ or greater is more problematic. There is a decrease in the migration rate between 1971-81 and 2001-11, but it is a small percentage point decrease on an initially low rate. The difference between the two rates is statistically significant although its substantive meaning must be questioned especially since the evidence produced by Champion and Shuttleworth (2016a) suggested that longer-distance migration in England and Wales had not experienced the same secular decline since the 1970s as observed in the USA by Cooke and others. However, if viewed as a percentage decline, a fall of nearly $16 \%$ between the two time periods is worth further commentary and some interesting contrasts between all address changes and these longer distance moves can be observed. The net effects of changes in population composition are small with the positive effects of increased education and shifts in SEG being outweighed by the effects of ageing and tenure. It is interesting to observe, however, that the greater share in the population with degrees has a slightly larger effect here since longer-distance moves are often associated with higher levels of education and it might be expected therefore that this compositional effect would have a greater influence at this distance band. The net effect of changes in behaviour (the coefficients part of the model) is also negative but most of this can be attributed to the constant term which more than fully 
counteracts the modelled rate increases for some sub-groups such as those without degrees (relative to those with) and the modelled increases across age. As before, the behavioural part of the model is more important than the composition section, and the importance of the constant suggests a universal effect that cuts across all population groups.

\section{Discussion}

The results presented are exploratory rather than definitive and should be interpreted with appropriate caution. Nevertheless, it is possible to be confident about the general factors that underlie the decline in all-address changing and moves of less than 10km, in particular between 1971-81 and 2001-11. Firstly, changes in population composition have played some role in the decrease as in the United States (Cooke, 2011), but, just as in the USA, they do not explain fully what has happened contributing at most between $35 \%-40 \%$ to the fall. This is likely to be an upper estimate since the exclusion of students, especially from the 2001-11 decade, exaggerates the impacts of population age shifts; the contribution of changes in age composition, and therefore of changing population structure in general, may thus be somewhat less than measured here. Despite this, the combined effects of age and housing tenure changes outweigh the upward pushing effects of increasing education, the growth of professional and technical occupations, and the decline in the proportion of married people. This is an important finding but it leaves more questions open than it answers since the majority of the decline in migration is explained by changes in the way that people are behaving, in other words rate or behavioural effects. These suggest that demographic sub-groups in 2001-11 simply behaved differently from 1971-81 in that they were less migratory in the latter decade. We do not know why this is the case, but it is possible to advance some informed hypotheses to guide future research from the analysis that has been done to date.

The cardinal points to note are that almost all demographic sub-groups for all-address changes and moves of $10 \mathrm{~km}$ or less appear to have experienced a fall in migration rates and that most of this decline has been at the spatial scale of moves of $10 \mathrm{~km}$ or less best represented by the all-address changing model. The importance of the constant term indicates that there is a general effect pushing down migration rates. This observation is sufficient - in combination with the evidence that changes in population composition contribute to, but do not fully explain, the decline - to suggest further avenues for analysis and enquiry. It seems there is something different about 2001-11 compared to 1971-81. This might be termed a long-term 'period effect' or a secular trend, perhaps secular rootedness (Cooke, 2011), that has acted to depress migration rates and change internal migratory behaviour generally. One part of this period effect might be the economic/business cycle. This acts across entire populations but on average it is probable that various cycles have balanced out across the two decades 
that have been the subject of the analysis; anyway, the migration decline appears to have started in the 1970s (Champion \& Shuttleworth, 2016b) and therefore predates the Great Recession of 2008 which appears the only plausible short-term period effect that would be a candidate to explain the much lower migration rates for all-address changes and less than $10 \mathrm{~km}$ in 2001-11. This suggests that there are longer-term period effects in operation which mean that the England and Wales of 2001-11 differed greatly from that of the 1970s, and which are particularly important for short-distance moves. These period factors are ignored by the models that underlie this analysis which concentrate on only the individual correlates of migration, and missing these factors would explain the large proportion of the differentials accounted for by rate effects, particularly the constant terms.

There are many possible migration drivers (see Green, 2018) that might cause deep-rooted structural changes of the sort that differentiate 2001-11 from the period thirty years before. These include changes in the regional geography of economic production, advances in transport which mean commuting over a variety of spatial scales is now easier than in the past, the growth of two-earner households, the expansion of higher education, and the increased use of electronic and internet-based communication technologies. These either singly or in combination have been advanced to explain the migration decline since the 1970s in the USA (Molloy, Smith \& Wozniak, 2011; Partridge et al., 2012). However, there are important differences between the cases of the USA and England and Wales; rather than being a decline across all spatial scales as in the USA (Cooke, 2018), the fall in England and Wales is concentrated at shorter distances. Moreover, it appears to be more marked for older people. All this directs attention to those factors that are primarily associated with shortdistance migration, and chief amongst these is the housing market. This suggests that efforts to understand migration declines in England and Wales might usefully be directed at exploring changes in the housing market and their effects on the rootedness of older people over and above the shifting shares of owner occupation, social renting and private renting.

The UK housing market is exceptional by international standards, being constrained by problems of affordability and supply, and has experienced the highest house price increases relative to wages of any OECD country (Hilber \& Vermeulen, 2016). This has been exacerbated by various aspects of government policy - the reliance on the housing market as a tool of economic policy combined with planning constraints, and the downplaying of the role of the social-rented sector and local authorities as housing providers. There has been a decline in the total number of dwellings completed in England 
from 378,320 in $1969-70$ to 168,350 in $2015-16^{1}$ whilst the number of annual dwellings required to meet need is estimated to be around 300,000 per year (Heath, 2014). House-price inflation may mean that owner occupiers become trapped and it might also mean that, for those already on the housing ladder, there are greater benefits from investing in an existing property and staying put than changing address (Hilber \& Vermeulen, 2016). This combination, not just the increase in owner occupation - its compositional effect - but also the type of owner occupation in terms of the wider price and economic context - its effect on behaviour or its rate effect - would seem to offer strong inducements not to move especially for older people. For younger people it has been noted that their main achievement is now to get a foot on the housing ladder and to leave the parental home. This might divert them into other tenure types like private and social renting, where available, but equally, where demand outstrips supply, lead to some young adults remaining in the parental home, a phenomenon that has been linked to migration slowdowns in other countries such as Italy, Japan and Australia (Bonifazi, Heins \& Tucci, 2018; Fielding, 2018; Bell, Wilson, Charles-Edwards \& Ueffing, 2018, respectively).

If this account has any truth, there ought to be 'frustrated movers' who would want to change address but are not able to do so. Unfortunately, there is very little secondary evidence on migration intentions-most examines the attitudes and experiences of people after they have moved - and there is even less data with sufficient temporal depth to examine how migration intentions, barriers and events have changed since the 1970s (Champion \& Shuttleworth, 2016b) so to develop these ideas further will require the collection of new data. Furthermore, it is by no means certain that the housing market on its own is the sole explanation; it might, for example, be that the migration-commuting nexus is also worthy of more consideration since longer commutes might reduce the need for address changing within the same labour market (although this would not avoid the need for longer-distance moves). There is evidence that in England and Wales longer-distance moves have only declined marginally (by 1.3 percentage points) or - using other metrics and data - not at all (Champion \& Shuttleworth, 2016a).

\section{Conclusions}

The results indicate the likely importance of compositional population changes as well as pointing out where it might be possible to search for more answers. The chief finding is that changing population make-up accounts for around $35 \%$ to $40 \%$ of the migration decline for all-address changes and shortdistance address changing in England and Wales with the rest attributable to changed behaviour and,

\footnotetext{
${ }^{1}$ Table 209, https://www.gov.uk/government/statistical-data-sets/live-tables-on-house-building, accessed April $25^{\text {th }} 2017$
} 
especially for the all-address changing model, a large constant term which suggests forces that cut across all population groups. As noted earlier, this $35 \%-40 \%$ might be an over estimate but this simply leaves more importance for changed behaviour and the constant term. The large constant term suggests long-term period effects, secular long-acting structural trends, that are driving migration rate changes - perhaps a British version of secular rootedness. It may well be that this British version of 'secular rootedness' is something to do with the housing market. This is implied by the fact that most of the change in England and Wales is over small spatial scales of $10 \mathrm{~km}$ where housing is important in motivating address changing and there is enough evidence of the peculiarities of the UK housing market not to rule this idea out of court completely.

What are the trends for the future? Many of the compositional changes noted between 1971 and 2001 will still trend in the same direction in the future; the population will age, and become more educated and white-collar, barring any unexpected major shocks. The compositional factors of the population will therefore still probably push migration rates downwards as in the past. However, there is room for uncertainty associated with the resurgence of the private-rental sector. By 2011, there were more private renters than in 2001, and this should have acted to push migration upwards through the decade as more sample members found themselves in this traditionally-mobile tenure. If this trend continues, then the next census in 2021 may yield different results. Despite this, however, there is no getting away from the fact that it is changed behaviour, people simply being less migratory, that is the main cause of migration decline in England and Wales and that without changed behaviour - and perhaps changed housing policies? - the population will not get more mobile.

Whether the decline is important is a topic for debate, but if thought has not yet been given to this by policymakers, it is recommended that it now is. Stable populations can equal stable communities - an ideal for some - but there can be substantial downsides. These include people struggling to be socially mobile since social mobility is often associated with residential relocation, the danger that people can live compartmentalised lives in spatial silos, and that adjustment to labour market changes can be hindered by spatial immobility. Some of these concerns might be unwarranted; perhaps commuting and electronic communications can compensate for residential immobility; perhaps the link between social and spatial mobility is being weakened; residential moves might now be less relevant because of other forms of daily, weekly and monthly mobility. However, little is yet known about these issues through the particular lens of 'migration slowdown' and so further research is needed.

The research challenge for the future is to understand more about why migratory behaviour is different now from what it was in the past and, especially, to get to grips more with the constant term. This can 
be termed 'secular rootedness' (Cooke, 2011), but it is necessary to probe behind this label to understand why people today are less mobile than in the past. Factors leading to more residential rootedness include increased social capital where community is valued more highly (Green, 2018) and the use of ICT (Cooke \& Shuttleworth, 2017), so further research is needed to consider how, where and why these factors operate. Ideally, therefore, it would have been useful to have included other social, labour market, technological and housing variables in the current models that would have encapsulated how the environment of the first decade of $21^{\text {st }}$ Century in England and Wales differed from that of the 1970s, but in practice that would have been problematic given the data and methods used. To take the research agenda further will thus require new approaches, data collection, and analyses. 


\section{References}

Bell, M., Wilson, T., Charles-Edwards, E., \& Ueffing, P.. (2018). The long-run decline in Australian internal migration intensities. In T. Champion, T. Cooke, I. Shuttleworth, (eds.), Internal migration in the developed world: Are we becoming less mobile? (pp. 147-172). London and New York: Routledge.

Blinder, A.S. (1973). Wage discrimination: Reduced form and structural estimates. Journal of Human Resources, 8(4), 436-455. doi: 10.2307/144855

Bonifazi, C., Heins, F., \& Tucci, E. (2018). Italy: internal migration in a low-mobility country. In T. Champion, T. Cooke, I. Shuttleworth, (eds.), Internal migration in the developed world: Are we becoming less mobile? (pp. 242-26). London and New York: Routledge.

Champion, T. (2005). Population movement within the UK. In R. Chappell (ed.), Focus on people and migration (pp. 91-113). Basingstoke, UK: Palgrave Macmillan.

Champion, T., \& Shuttleworth, I. (2015). Are people moving home less? An analysis of address changing in England and Wales, 1971-2011, using the ONS longitudinal study. SERC Discussion Papers, SERC DP $0177 . \quad$ London: Spatial Economics Research Centre. http://www.spatialeconomics.ac.uk/textonly/SERC/publications/download/sercdp0177.pdf

Champion, T., \& Shuttleworth, I. (2016a). Is longer-distance migration slowing? An analysis of the annual record for England and Wales since the 1970s. Population, Space and Place. doi: $10.1002 / p s p .2024$

Champion, T., \& Shuttleworth, I. (2016b). Are people changing address less? An analysis of migration within England and Wales, 1971-2011, by distance of move. Population, Space and Place. doi: 10.1002/psp.2026

Champion, T., Cooke, T., \& Shuttleworth, I. (eds.) (2018). Internal migration in the developed world: Are we becoming less mobile? London and New York: Routledge.

Cooke, T.J. (2011). It is not just the economy: Declining migration and the rise of secular rootedness. Population, Space and Place 17(3), 193-203. doi: 10.1002/psp.670

Cooke, T.J. (2013). Internal migration in decline. The Professional Geographer, 65(4), 664-675. doi: $\underline{10.1080 / 00330124.2012 .724343}$

Cooke, T. (2018). United States: cohort effects on the long-term decline in migration rates. In T. Champion, T. Cooke, I. Shuttleworth (eds.), Internal migration in the developed world: Are we becoming less mobile? (pp. 101-119). London and New York: Routledge.

Cooke, T., \& Shuttleworth, I. (2017). Migration and the internet. Migration Letters, in press. 
Coulter, R., van Ham, M., \& Findlay, A.M. (2015). Re-thinking residential mobility Linking lives through time and space. Progress in Human Geography, 40(3), 352-374. doi: $10.1177 / 0309132515575417$

Coulter, R., \& Scott, J. (2015). What motivates residential mobility? Re-examining self-reported reasons for desiring and making residential moves. Population, Space and Place, 21(?), 354-371. doi: $10.1002 / p s p .1863$

Fielding, T. (2018). Japan: internal migration trends and processes since the 1950s. In T. Champion, T. Cooke, I. Shuttleworth (eds.), Internal migration in the developed world: Are we becoming less mobile? (pp. 173-202). London and New York: Routledge.

Fischer, C.S. (2002). Ever-more rooted Americans. City \& Community, 1(2), 177-198. doi: $10.1111 / 1540-6040.00016$

Gordon, I.R. (1982). The analysis of motivation-specific migration streams. Environment and Planning A, 14(1), 5-20. doi: 10.1068/a140005

Green, A. (2018). Understanding the drivers of internal migration. In T. Champion, T. Cooke, I. Shuttleworth (eds.), Internal migration in the developed world: Are we becoming less mobile? (pp. 31-55). London and New York: Routledge.

Heath, S. (2014). Housing demand and need (England), SN06921. London: Social Policy Section, House of Commons Library.

http://www.legco.gov.hk/general/english/library/stay_informed_overseas_policy_updates/hou sing_demand_and_need.pdf

Hilber, C., \& Vermeulen, W. (2016). The impact of supply constraints on house prices in England. The Economic Journal, 126(591), 358-405. doi: 10.1111/ecoj.12213

HM Treasury (2015). Fixing the foundations: Creating a more prosperous nation. London: HM Treasury, CM9098, July 2015. https://www.gov.uk/government/publications/fixing-thefoundations-creating-a-more-prosperous-nation

Jann, B. (2008). Oaxaca: Stata module to compute the Blinder-Oaxaca decomposition. Boston, MA: Boston College Department of Economics.

Kaplan, G., \& Schulhofer-Wohl, S. (2012). Interstate migration has fallen less than you think: Consequences of hot desk imputation in the Current Population Survey. Demography, 49(3), 1061-1074. doi: 10.1007/s13524-012-0110-3

Kitching, R. (1990). Migration behaviour among the unemployed and low-skilled. In Labour migration: The internal geographical mobility of labour in the developed world (pp.172-190). London: David Fulton Publishers Ltd.

Molloy, R., Smith, C.L., \& Wozniak, A. (2011). Internal migration in the United States. Journal of Economic Perspectives, 25(3), 173-196. doi: 10.1257/jep.25.3.173 
Niedomysl, T. (2011). How migration motives change over migration distance: Evidence on variation across socio-economic and demographic groups. Regional Studies, 45(6), 843-855. doi: $\underline{10.1080 / 00343401003614266}$

Oaxaca, R. (1973). Male-female wage differentials in urban labor markets, International Economic Review, 14(3), 693-709. doi: 10.2307/2525981

Partridge, M.D., Rickman, D.S., Olfert, M.R., \& Ali, K. (2012), Dwindling US internal migration: Evidence of spatial equilibrium or structural shifts in local labor markets? Regional Science and Urban Economics, 42(1-2), 375-388. doi: 10.1016/i.regsciurbeco.2011.10.006

Ravenstein, E.G. (1885). The laws of migration. Journal of the Statistical Society of London, 48: 167235. https://cla.umn.edu/sites/cla.umn.edu/files/the_laws_of_migration.pdf

Sheller, M., \& Urry. J. (2006). The new mobilities paradigm. Environment and Planning A, 38(2), 207226. doi: $10.1068 / a 37268$

StataCorp (2015). Stata statistical software: Release 14. College Station, TX: StataCorp LP. https://www.stata.com/support/faqs/resources/citing-software-documentation-faqs/

Thomas, M., Stillwell, J., \& Gould, M. (2015). Modelling multilevel variations in distance moved between origins and destinations in England and Wales. Environment and Planning A, 47(4), 996-1014. doi: 10.1068/a130327p

Wolf, D.A., \& Longino, C.F. (2005). Our 'increasingly mobile society'? The curious persistence of a false belief. The Gerontologist, 45(1), 5-11. doi: 10.1093/geront/45.1.5

Zelinsky, W. (1971). The hypothesis of the mobility transition. Geographical Review, 61(2), 219-249. http://www.jstor.org/stable/213996 


\section{Tables}

Table 1: Explanatory variable descriptions and counts

\begin{tabular}{|c|c|c|}
\hline Explanatory variable & $1971-81$ & 2001-11 \\
\hline \multicolumn{3}{|l|}{ Gender } \\
\hline Male (reference) & 129697 & 141593 \\
\hline Female & 144445 & 156307 \\
\hline \multicolumn{3}{|l|}{ Age group } \\
\hline 16-24 (reference) & 47612 & 26102 \\
\hline $25-34$ & 55039 & 60034 \\
\hline $35-44$ & 53572 & 69693 \\
\hline $45-54$ & 53109 & 63227 \\
\hline $55-64$ & 43168 & 47957 \\
\hline $65-74$ & 21642 & 30887 \\
\hline \multicolumn{3}{|l|}{ Country of birth } \\
\hline UK born (reference) & 256139 & 267743 \\
\hline Not UK Born & 18003 & 30157 \\
\hline \multicolumn{3}{|l|}{ Education } \\
\hline Degree (reference) & 19812 & 60374 \\
\hline No degree & 254330 & 237526 \\
\hline \multicolumn{3}{|l|}{ Marital status } \\
\hline Single (reference) & 51518 & 75644 \\
\hline Married & 205616 & 185028 \\
\hline Widowed & 13398 & 10697 \\
\hline Divorced & 3610 & 26531 \\
\hline \multicolumn{3}{|l|}{ Housing tenure } \\
\hline Owner occupied (reference) & 141440 & 231380 \\
\hline Social renting & 81736 & 41038 \\
\hline Private renting & 47795 & 23881 \\
\hline Communal & 3171 & 1601 \\
\hline \multicolumn{3}{|l|}{ Economic activity } \\
\hline Employed full-time (reference) & 147222 & 133891 \\
\hline Employed part-time & 26076 & 41206 \\
\hline Self employed & 14531 & 27610 \\
\hline Unemployed & 6317 & 9141 \\
\hline Sick & 3882 & 15232 \\
\hline Retired & 17048 & 39393 \\
\hline Inactive & 59066 & 31427 \\
\hline \multicolumn{3}{|l|}{ Socio-economic group } \\
\hline Professional (reference) & 7175 & 13920 \\
\hline Intermediate & 34702 & 86947 \\
\hline Skilled non-manual & 44353 & 69941 \\
\hline Skilled manual & 56974 & 54195 \\
\hline Part skilled & 41044 & 45681 \\
\hline Unskilled & 14713 & 14013 \\
\hline Armed forces & 1295 & 857 \\
\hline Other & 73886 & 12346 \\
\hline \multicolumn{3}{|l|}{ Region } \\
\hline South East (reference) & 103273 & 114788 \\
\hline South West & 22798 & 28835 \\
\hline Midlands & 50482 & 56184 \\
\hline North & 82396 & 81764 \\
\hline Wales & 15193 & 16329 \\
\hline \multicolumn{3}{|l|}{ Outcome variables } \\
\hline All address changes & 142009 & 122173 \\
\hline Moves $=>50 \mathrm{~km}$ & 23407 & 21493 \\
\hline Moves $<10 \mathrm{~km}$ & 96093 & 71934 \\
\hline Total & 274142 & 297900 \\
\hline
\end{tabular}

Source: calculated from ONS Longitudinal Study. Crown copyright data. 
Table 2: Summary descriptive statistics

\begin{tabular}{|c|c|c|c|c|c|c|c|c|}
\hline \multirow[t]{2}{*}{$\begin{array}{l}\text { Characteristic at start of } \\
\text { decade }\end{array}$} & \multicolumn{3}{|c|}{$\begin{array}{l}\text { Composition at start of } \\
\text { decade (\%) }\end{array}$} & \multicolumn{3}{|c|}{$\begin{array}{l}\text { All address change rate for } \\
\text { decade (\%) }\end{array}$} & \multicolumn{2}{|c|}{$\begin{array}{l}\text { \%point change } \\
71-81 \text { to } 01-11\end{array}$} \\
\hline & $\begin{array}{l}1971- \\
1981\end{array}$ & $\begin{array}{l}2001- \\
2011\end{array}$ & $\begin{array}{l}\text { \%point } \\
\text { change }\end{array}$ & $\begin{array}{l}1971- \\
1981\end{array}$ & $\begin{array}{l}2001- \\
2011\end{array}$ & $\begin{array}{l}\text { \%point } \\
\text { change }\end{array}$ & $\begin{array}{l}\text { Under } \\
10 \mathrm{~km}\end{array}$ & $\begin{array}{l}50 \mathrm{~km} \\
\text { or } \\
\text { more }\end{array}$ \\
\hline \multicolumn{9}{|l|}{ Gender } \\
\hline Male & 47.3 & 47.5 & +0.2 & 53.2 & 42.0 & -11.2 & -10.3 & -1.0 \\
\hline Female & 52.7 & 52.5 & -0.2 & 50.6 & 40.1 & -10.5 & -8.6 & -0.6 \\
\hline \multicolumn{9}{|l|}{ Age } \\
\hline $16-24$ & 17.4 & 8.8 & -8.6 & 85.6 & 79.2 & -6.4 & -5.0 & -0.8 \\
\hline $25-34$ & 20.1 & 20.2 & +0.1 & 63.9 & 63.3 & -0.6 & -1.7 & -0.7 \\
\hline $35-44$ & 19.5 & 23.4 & +3.9 & 43.3 & 40.0 & -3.3 & -3.8 & -0.4 \\
\hline $45-54$ & 19.4 & 21.2 & +1.9 & 36.1 & 28.1 & -8.0 & -9.1 & +0.0 \\
\hline $55-64$ & 15.8 & 16.1 & +0.4 & 37.6 & 24.0 & -13.6 & -11.9 & -1.6 \\
\hline $65-74$ & 7.9 & 10.4 & +2.5 & 36.7 & 20.5 & -16.2 & -14.2 & -1.5 \\
\hline \multicolumn{9}{|l|}{ Country of birth } \\
\hline UK & 93.4 & 89.9 & -3.6 & 51.4 & 41.3 & -10.0 & -8.9 & -1.2 \\
\hline Not UK & 6.6 & 10.1 & +3.6 & 58.2 & 38.3 & -19.9 & -16.1 & -2.3 \\
\hline \multicolumn{9}{|l|}{ Marital status } \\
\hline Single & 18.8 & 25.4 & +6.6 & 72.4 & 62.6 & -9.8 & -8.6 & -0.6 \\
\hline Married & 75.0 & 62.1 & -12.9 & 47.1 & 32.7 & -14.4 & -11.5 & -2.0 \\
\hline Widowed & 4.9 & 3.6 & -1.3 & 41.9 & 25.5 & -16.4 & -15.4 & -1.0 \\
\hline Divorced & 1.3 & 8.9 & +7.6 & 63.0 & 43.6 & -19.4 & -15.8 & -2.5 \\
\hline \multicolumn{9}{|l|}{ Housing tenure } \\
\hline Owner occupied & 51.6 & 77.7 & +26.1 & 46.8 & 37.4 & -9.4 & -6.1 & -2.8 \\
\hline Social renting & 29.8 & 13.8 & -16.0 & 49.4 & 40.1 & -9.3 & -9.6 & +0.3 \\
\hline Private renting & 17.4 & 8.0 & -9.4 & 69.0 & 74.9 & +5.9 & -2.6 & +4.2 \\
\hline Communal & 1.2 & 0.5 & -0.6 & 76.7 & 80.6 & +4.0 & -3.8 & +6.2 \\
\hline \multicolumn{9}{|l|}{ Economic activity } \\
\hline Employed full-time & 53.7 & 44.9 & -8.8 & 56.4 & 48.7 & -7.8 & -8.5 & -0.4 \\
\hline Employed part-time & 9.5 & 13.8 & +4.3 & 42.1 & 35.8 & -6.3 & -5.1 & -1.5 \\
\hline Self employed & 5.3 & 9.3 & +4.0 & 52.6 & 40.0 & -12.6 & -11.0 & -0.6 \\
\hline Unemployed & 2.3 & 3.1 & +0.8 & 62.6 & 51.2 & -11.4 & -9.4 & -1.8 \\
\hline Sick & 1.4 & 5.1 & +3.7 & 48.1 & 34.9 & -13.2 & -11.8 & +0.2 \\
\hline Retired & 6.2 & 13.2 & +7.0 & 36.7 & 20.7 & -16.0 & -13.8 & -1.5 \\
\hline Inactive & 21.6 & 10.6 & -11.0 & 47.8 & 41.5 & -6.3 & -4.3 & -1.6 \\
\hline \multicolumn{9}{|l|}{ Education } \\
\hline Degree & 7.2 & 20.3 & +13.0 & 58.1 & 47.0 & -11.0 & -4.1 & -6.4 \\
\hline No degree & 92.8 & 79.7 & -13.0 & 51.3 & 39.5 & -11.8 & -9.5 & -1.8 \\
\hline \multicolumn{9}{|l|}{ Socio-economic group } \\
\hline Professional & 2.6 & 4.7 & +2.1 & 58.4 & 43.9 & -14.6 & -7.2 & -4.5 \\
\hline Intermediate & 12.7 & 29.2 & +16.5 & 55.4 & 44.1 & -11.3 & -5.9 & -4.4 \\
\hline Skilled non-manual & 16.2 & 23.5 & +7.3 & 58.8 & 41.9 & -16.9 & -9.6 & -3.9 \\
\hline Skilled manual & 20.8 & 18.2 & -2.6 & 50.7 & 38.7 & -12.0 & -11.9 & +0.0 \\
\hline Part skilled & 15.0 & 15.3 & +0.4 & 49.6 & 38.2 & -11.4 & -10.6 & -0.5 \\
\hline Unskilled & 5.4 & 4.7 & -0.7 & 48.7 & 34.6 & -14.1 & -15.1 & +0.2 \\
\hline Armed forces & 0.5 & 0.3 & -0.2 & 90.6 & 73.8 & -16.8 & -0.1 & -18.0 \\
\hline Other & 27.0 & 4.1 & -22.8 & 47.3 & 37.0 & -10.3 & -5.4 & -3.5 \\
\hline \multicolumn{9}{|l|}{ Region } \\
\hline South East & 37.7 & 38.5 & +0.9 & 54.1 & 44.6 & -9.6 & -7.2 & -2.0 \\
\hline South West & 8.3 & 9.7 & +1.4 & 51.0 & 42.3 & -8.7 & -7.9 & -1.6 \\
\hline Midlands & 18.4 & 18.9 & +0.4 & 49.9 & 39.1 & -10.8 & -10.1 & -0.7 \\
\hline North & 30.1 & 27.5 & -2.6 & 51.2 & 38.1 & -13.2 & -11.5 & -1.3 \\
\hline Wales & 5.5 & 5.5 & -0.1 & 46.8 & 35.2 & -11.6 & -11.4 & -0.7 \\
\hline Total & 100.0 & 100.0 & 0.0 & 51.8 & 41.0 & -10.8 & -9.4 & -1.3 \\
\hline
\end{tabular}

Source: calculated from ONS Longitudinal Study. Crown copyright data.

Note: Population comprises all LS members aged 15-74 at the start of the decade with a record in the following census. excluding students at start of the decade: $\mathrm{N}$ for 1971-1981 274,142; N for 2001-2011 297,900. 
Table 3: Summary of Oaxaca-Blinder decomposition results

\begin{tabular}{|c|c|c|c|c|c|c|}
\hline Variable & \multicolumn{2}{|c|}{ All moves } & \multicolumn{2}{|c|}{ Moves $=>50 \mathrm{~km}$} & \multicolumn{2}{|c|}{ Moves $<10 \mathrm{~km}$} \\
\hline $1971-81$ rate & 51.80 & & 8.54 & & 35.05 & \\
\hline 2001-11 rate & 41.01 & & 7.21 & & 25.68 & \\
\hline Difference & -10.79 & & -1.33 & & -9.38 & \\
\hline Composition effect & Coefficient & $\%$ & Coefficient & $\%$ & Coefficient & $\%$ \\
\hline Region & 0.10 & 0.94 & 0.09 & 6.76 & -0.05 & -0.51 \\
\hline Gender & 0.00 & 0.01 & 0.00 & 0.03 & 0.00 & 0.00 \\
\hline Age & -3.61 & -33.50 & -0.48 & -36.39 & -2.43 & -25.93 \\
\hline Country of birth & -0.09 & -0.81 & -0.07 & -4.94 & 0.03 & 0.31 \\
\hline Education & 0.32 & 2.95 & 0.51 & 38.16 & -0.37 & -3.93 \\
\hline Marital status & 0.99 & 9.16 & 0.08 & 6.09 & 0.60 & 6.42 \\
\hline Tenure & -2.64 & -24.44 & -0.77 & -58.55 & -1.47 & -15.70 \\
\hline Economic activity & -0.12 & -1.10 & -0.15 & -11.42 & 0.06 & 0.69 \\
\hline Socio-economic group & 1.13 & 10.45 & 0.84 & 63.66 & -0.35 & -3.69 \\
\hline Total & -3.92 & -36.34 & 0.04 & 3.40 & -3.97 & -42.34 \\
\hline \multicolumn{7}{|l|}{ Behaviour effect } \\
\hline Region & -0.97 & -8.99 & 0.45 & -33.91 & -1.74 & -18.52 \\
\hline Gender & -0.39 & -3.58 & -0.20 & -14.85 & -0.07 & -0.76 \\
\hline Age & 0.93 & 8.62 & 1.17 & 88.67 & -2.01 & -21.46 \\
\hline Country of birth & -0.83 & -7.66 & -0.06 & -4.57 & -0.70 & -7.45 \\
\hline Education & 1.21 & 11.21 & 2.17 & 164.31 & -0.27 & -2.87 \\
\hline Marital status & -1.26 & -11.67 & -0.88 & -66.14 & -0.28 & -3.00 \\
\hline Tenure & 0.41 & 3.84 & 0.86 & 64.94 & -0.78 & -8.32 \\
\hline Economic activity & -0.42 & -3.87 & -0.01 & -0.41 & 0.08 & 0.84 \\
\hline Socio-economic group & 1.28 & 11.89 & -0.07 & -4.93 & -0.56 & -5.94 \\
\hline Constant & -7.88 & -73.04 & -5.99 & -452.82 & 1.22 & 12.97 \\
\hline Total & -7.90 & -73.25 & -2.54 & -191.89 & -5.11 & -54.50 \\
\hline \multicolumn{7}{|l|}{ Residual } \\
\hline Region & -0.09 & -0.81 & 0.00 & 0.16 & -0.08 & -0.81 \\
\hline Gender & 0.00 & -0.02 & 0.00 & -0.06 & 0.00 & 0.00 \\
\hline Age & -0.06 & -0.52 & -0.13 & -9.75 & 0.25 & 2.67 \\
\hline Country of birth & 0.29 & 2.69 & 0.02 & 1.60 & 0.25 & 2.62 \\
\hline Education & 0.20 & 1.83 & 0.36 & 26.87 & -0.04 & -0.47 \\
\hline Marital status & 0.30 & 2.76 & -0.04 & -2.82 & 0.33 & 3.54 \\
\hline Tenure & 0.49 & 4.53 & 1.00 & 75.93 & -0.91 & -9.70 \\
\hline Economic activity & -0.04 & -0.41 & -0.20 & -15.20 & 0.13 & 1.43 \\
\hline Socio-economic group & -0.05 & -0.47 & 0.16 & 11.75 & -0.23 & -2.43 \\
\hline Total & 1.03 & 9.59 & 1.17 & 88.49 & -0.30 & -3.16 \\
\hline Overall total & -10.79 & -100.00 & -1.33 & -100.00 & -9.38 & -100.00 \\
\hline
\end{tabular}

Source: calculated from ONS Longitudinal Study. Crown copyright data. 